\title{
A desinformação como pilar da intersecção entre letramento informacional e tratamento temático da informação
}

\author{
Disinformation as support of the intersection between \\ informational literacy and subject representation
}

\begin{abstract}
Lais Pereira de Oliveira a,*
Maria Aparecida Rodrigues de Souza b (D)

RESUMO: Aborda a intersecção entre letramento informacional e tratamento temático, sob a égide do fenômeno da desinformação. Tenciona incorporar a perspectiva tecnicista biblioteconômica à concepção do usuário, na seleção e manipulação da informação, considerando o falseamento e a crescente distorção de conteúdos, característica das mídias sociais, que incita a repensar e rediscutir o fenômeno na ótica informacional. Objetiva discorrer teoricamente sobre o vínculo das instâncias de processamento e de uso da informação, na figura do tratamento temático e do letramento informacional, tendo por base o pilar da desinformação. Constitui pesquisa teórico-descritiva de natureza qualitativa, sustentada em revisão de literatura na área de Ciência da Informação. Prioriza artigos de periódicos obtidos na Base de Dados Referencial de Artigos de Periódicos em Ciência da Informação, mediante busca pelo termo desinformação, bem como trabalhos apresentados em eventos e capítulos de livros, substanciais à caracterização do letramento informacional e do tratamento temático da informação. Demonstra, no enlace teórico, a necessária atuação conjunta de bibliotecários, instituições e usuários no combate à desinformação. Conclui-se que a integração do letramento informacional e do tratamento temático da informação é, de certo modo, incitada pela cultura da desinformação, representando um meio para o manuseio analítico dos distintos conteúdos e o real combate à sua distorção e desvirtuação. Todavia, dirimi-la passa pela ação integrada de bibliotecários, instituições e usuários.
\end{abstract}

Palavras-chave: Desinformação; Tratamento da Informação; Busca da Informação.

ABSTRACT: Its approaches the intersection between information literacy and subject representation, under influence of the phenomenon of disinformation. It intends to incorporate the librarian technicist perspective with the user's conception, in the selection and manipulation of information, considering the falsification and the growing distortion of contents, characteristic of social media, which encourages rethinking and rediscussing the phenomenon from an informational perspective. It aims to talk theoretically the link between the instances of information processing and use, in the form of subject representation and information literacy, based on the pillar of disinformation. It constitutes qualitative theoretical-descriptive research, based on literature review in the area of Library and Information Science. Focuses in journal articles obtained from the Base de Dados Referencial de Artigos de Periódicos em Ciência da Informação, searching to the term misinformation, besides proceedings and book chapters, essential for characterization of the information literacy and subject representation. It demonstrates, in the theoretical link, the necessary joint action of librarians, institutions and users in the decrease of the disinformation. It is concluded that the integration of information literacy and subject representation is, in a sense, instigate by the culture of disinformation, representing a means for the analytical handling of the different contents and the real decrease in your distortion. However, solving it requires integrated action by librarians, institutions and users.

Keywords: Disinformation; Information Processing; Information Search.

a Faculdade de Informação e Comunicação, Universidade Federal de Goiás, Goiânia, GO, Brasil.

b Biblioteca Atena, Instituto Federal de Educação Profissional, Científica e Tecnológica de Goiás, Goiânia, GO, Brasil.

* Correspondência para/Correspondence to: Lais Pereira de Oliveira. Endereço: Universidade Federal de Goiás, Faculdade de Informação e Comunicação - Avenida Esperança, s/n - Campus Samambaia74690900 - Goiânia, GO - Brasil. E-mail: laispereira2@ufg.br.

Recebido em/Received: 27/02/2021; Aprovado em/Approved: 16/06/2021.

Artigo publicado em acesso aberto sob licença CC BY 4.0 Internacional ()(1) 


\section{INTRODUÇÃO}

Informar-se é uma necessidade estabelecida continuamente, erigida em torno de demandas individuais e também coletivas, com fins educacionais, instrutivos, comunicacionais, noticiosos, científicos, técnicos ou laborais. Todavia, não é apenas a informação genuína e confiável que circula e alcança seu público; a desinformação desafia a pesquisa, assim como a recuperação e a apropriação de conteúdos (Santos, Santos, Lavigne 2020).

Substrato central no propósito de desinformar, a manipulação intencional de informações gera um compartilhamento em cadeia, amplificado pelas mídias sociais. A disseminação sem checagem da consistência do conteúdo acaba se tornando a regra, propagando uma cultura da desinformação, uma vez que emplaca discursos e insere pautas à revelia de qualquer exame ou averiguação.

Destarte, há sérias implicações informacionais no caráter de desinformar, compelidas pelo falseamento e pela distorção, no que a área de Biblioteconomia e Ciência da Informação muito tem a agregar. Sobretudo pelas instâncias intermediária e final do ciclo informacional, em torno das quais se estabelecem acurados processos de tratamento e disseminação, no entendimento de que a informação processada será determinante na busca e recuperação, tornando-se acessível (Baptista 1994).

Desse modo, a pesquisa em questão objetiva discorrer teoricamente sobre o vínculo das instâncias de processamento e de uso da informação, na figura do tratamento temático e do letramento informacional, tendo por base o pilar da desinformação. Nesse sentido, avança sobre a problemática teorizante e reducionista do trato informacional ao aspecto técnico e, ainda, da passividade do usuário enquanto condicionante da atuação bibliotecária, tendo como questão de pesquisa: quais os vínculos possíveis entre tratamento temático e letramento informacional no cenário de desinformação ora instalado? Considera, pois, a necessária evidência do caráter intelectual da representação por assunto e da participação ativa do produtor de conteúdos, no deslinde do fenômeno da desinformação.

Advoga-se então, no presente estudo, pelo intrincado relacionamento entre letramento informacional (LI) e tratamento temático da informação (TTI), aqui postulados em caráter insigne e alijado do tecnicismo documentário. Mormente, são discutidos sobre o prisma da busca seletiva e consciente da informação, atrelada à ação organizativa reflexiva, pontual e pregressa sobre esta, principalmente considerando seu conteúdo, basilar na pesquisa por assunto. Entretanto, o pressuposto investigativo estende-se até a compreensão da desinformação como sustentáculo desse entrecorte letramento - tratamento, sinalizando para o protagonismo do bibliotecário tanto quanto do usuário nesse deslinde.

Para tanto, emprega pesquisa teórico-descritiva, de natureza qualitativa. A base é a revisão de literatura, que, para o tema central da desinformação, prioriza busca sistemática pelo termo na Base de Dados Referencial de Artigos de Periódicos em Ciência da Informação (BRAPCI), tendo em vista o caráter renovado das discussões a seu respeito sob a forma de artigos. Já para o enlace letramento - tratamento, interpõe-se também em publicações de outra ordem, como trabalhos apresentados em eventos e capítulos de livros.

A prospecção na BRAPCI foi realizada ao longo do mês de dezembro de 2020. Conduziu-se busca pelo termo "desinformação", junto ao campo de título, com filtro temporal entre os anos de 1972 a 2020, que resultou em 37 registros. A seleção dos 
artigos, para fundamentação da discussão teórica, observou a aderência temática ao tema, a partir da leitura de título, resumo e palavras-chave. Embora, fundamentalmente, tenham sido considerados aqueles detidos à abordagem sobre o fenômeno da desinformação, também foram incluídos alguns trabalhos sob a ótica da pós-verdade, das fake news e da infodemia que, entende-se, enriquecem a perspectiva analítico-descritiva acerca do ato desinformacional.

Considerando se tratar, aqui, de pesquisa teórica, os artigos sobre desinformação foram substancialmente abarcados a partir da fundamentação dada ao assunto, para contributo referencial às discussões sobre o enlace letramento - tratamento. Todavia, em razão de abordagens pregressas e longevas, na área de Biblioteconomia e Ciência da Informação, acerca dos temas letramento informacional e tratamento temático, optou-se por buscar referenciais a seu respeito em fontes de caráter efêmero e permanente, na forma de trabalhos apresentados em eventos e capítulos de livro.

A pesquisa pode contribuir com a percepção do fenômeno da desinformação para além do escopo tecnológico, social, político e comunicacional, que tradicionalmente o envolve. Além disso, pode explicitar um novo cenário de atuação do bibliotecário, em conjunção com o usuário, no auxílio de outros profissionais na busca resoluta de soluções para o fenômeno da desinformação.

\section{O CONCEITO E O CONTEXTO DA DESINFORMAÇÃO}

Pensar a desinformação passa, antes de mais nada, pela reflexão da própria informação e de sua atuação incisiva em nossos procedimentos e operações. Afinal, "o surgimento da chamada sociedade da informação tem trazido novas formas de pensar sobre as atividades humanas e sua relação com a informação e o conhecimento" (Ripoll, Matos 2020a, p. 211). O fenômeno da desinformação, como se apresenta, está entre esses novos aspectos a serem discutidos e explorados, a fim de melhor compreendê-lo e adquirir meios para seu deslinde ou minimização.

Nesse contexto, qualidade da informação e atendimento das necessidades informacionais tornam-se, também, temas muito pesquisados (Brito, Pinheiro 2015). Outrossim, há necessidade de novos questionamentos, "especialmente nas áreas que trabalham diretamente com questões epistemológicas ligadas à informação" (Ripoll, Matos 2020b, p. 88). E aqui entra a área de Biblioteconomia e Ciência da Informação, historicamente devotada ao universo informacional sobretudo pelas vias de sua organização, disseminação e uso, cada vez mais desafiadas no abnegado mar de desinformação ora instalado.

Desinformação congrega uma miríade de significados (Brito, Pinheiro 2015) mas, grosso modo, evoca a ideia da ausência de informação, isto é, aquilo que provoca sentido contrário ao ato de informar por não postular veracidade e, assim, não reunir a robustez necessária para se constituir como informação. Nessa medida, "pode-se dizer que a informação para ser informação parte do princípio da verdade" (Oliveira 2020, p. 177).

A desinformação, portanto, "compreende, de forma geral, uma série de conceitos que são o oposto do ato de informar" (Ripoll, Matos 2020b, p. 99). Wilke (2020/2021) entende a desinformação como uma consequência das notícias fraudulentas. Santos, Santos e Lavigne (2020) caracterizam-na como elemento de contorno convincente, envolvendo notícias distorcidas que dissimulam a verdade. 
Via de regra, então, a desinformação está presente quando se tem um contexto de produção que age com intenção de enganar (Vignoli, Rabello, Almeida 2021). Furtado e Oliveira (2020, p. 113), também nesse entendimento, destacam que:

\begin{abstract}
A desinformação é estrategicamente imperceptível e se projeta em convencer um público a consentir com base em interpretações e opiniões discretamente formuladas, uma informação como "verdadeira" e a partir disso adequar-se e propagar. Em geral essas informações não dispõem de clareza que informe origem ou contexto, mas estrategicamente estão bem elaboradas para atingir e causar os mais diversos tipos de reação.
\end{abstract}

Em função disso, ainda que contraditório, o substrato "desinformacional" corrompe, destrói e prevalece em detrimento da busca por informar e conhecer, legitimamente instituída, sustentada e cuidadosamente trabalhada, inclusive pela Ciência da Informação, que justamente nessa missão teve origem e, primordialmente, "tem seu engajamento mais fortemente voltado para a criação e como se dão os fluxos informacionais, mas ainda examina timidamente a questão da desinformação" (Conde, Alcará 2018, p. 1616).

Entretanto, a desinformação não surgiu recentemente. Ela sempre existiu (Zattar 2017). Na realidade, "é um conceito antigo que nasce ligado a projetos militares de contrainformação e espionagem, mas extrapola para os meios de comunicação e para aparelhos privados e estatais" (Brisola, Bezerra 2018, p. 3319).

Ademais, em se tratando das características da desinformação, é possível destacar:

\footnotetext{
1. A desinformação como atividade governamental ou militar;

2. Serviços de notícias, que disseminam desinformação;

3. Desinformação planejada, com algum propósito;

4. Nem sempre a desinformação surge da organização ou do indivíduo que pretende enganar;

5. É normalmente escrita ou verbal, mas também pode estar contida ou constituir imagens (fotografias adulteradas);

6. É distribuída de forma descontrolada por qualquer pessoa que tenha, por exemplo, assinatura em um jornal, TV ou com acesso a internet. Também pode ser destinada a organizações específicas. (Vignoli, Rabello, Almeida 2021, p. 9-10)
}

Um amplo repertório de estruturas e meios acaba, pois, suplantado pela desinformação. Ferreira, Lima e Souza (2021) falam de uma verdadeira mutação nos fluxos informacionais advindos dos canais eletrônicos de comunicação. Fato é que, informações falsas, eclodem com força no ambiente digital, onde encontram repercussão massiva (Santos, Santos, Lavigne 2020), sobretudo a partir do ano de 2016, em que ocorre a campanha presidencial norte-americana e o caso Brexit (Oliveira 2020). Tais acontecimentos acabaram permeados por informações falsas, altamente disseminadas nas mídias sociais (Conde, Alcará 2018).

Pode-se afirmar, inclusive, que a desinformação constitui-se como um construto enunciativo. E a web é justamente o canal que favorece sua produção e transmissão (Vignoli, Rabello, Almeida 2021), em uma diversidade de estruturas, mídias e portais. Por isso é justamente à web que a desinformação acaba sendo intimamente associada, principalmente às mídias sociais nela contempladas (Furtado, Oliveira 2020; Zattar 2017). 
Ocorre, pois, que o contexto hodierno das mídias sociais, em sua vultosa condição de difusão de conteúdos, traz a desinformação novamente à tona, tanto quanto a necessidade de abordá-la e procurar compreendê-la. Embora ela seja, fundamentalmente, algo complexo e delicado, sobretudo no que se refere à sua contenção. Afinal, "se a informação é insumo da verdade, no atual contexto, é também da própria pós-verdade” (Bernardino, Sampaio 2019, p. 150).

Basicamente, então, "um dos pressupostos para o combate ou proteção das pessoas e grupos sociais contra o avanço da desinformação é a diferenciação entre a informação legítima e a falsa informação, ou má informação" (Ripoll, Matos 2020a, p. 223). Apesar disso, a realidade é que "falsas informações estão, cada vez mais, sendo utilizadas e atingem a boa fé das pessoas" (Oliveira, 2020 p. 180). Os estragos, portanto, são potencializados conforme elas se espalham, até porque desinformação é uma forma velada de legitimação de desigualdades e opressões (Costa, Melo, Silva 2020).

Os prejuízos da desinformação são inúmeros, a começar pelo impacto nas esferas social e política. Conde e Alcará (2018, p. 1615) lembram que "o alastramento de notícias falsas é muito superior quando o momento político é mais turbulento e favorece o acirramento de extremismos", enquanto Revez e Corujo (2021) reforçam que estas representam uma séria ameaça à própria democracia.

Dito de outro modo, nos casos de política eleitoral, por exemplo, a desinformação pode ser desastrosa e até mesmo perigosa (Vignoli, Rabello, Almeida 2021). O envoltório falseado segrega fatos, manipula e dissemina de forma massiva, para o cumprimento de propósitos específicos. Ao circular, ganha força e passa a ser reafirmado como verdade, dificultando ainda mais sua desmistificação.

Além disso, embora não corporificada enquanto informação real e verdadeira, a desinformação acaba sendo absorvida por aqueles cuja concepção se assemelha ao teor do conjunto difundido. Inclusive, há estudos "que mostram que o ser humano tem uma tendência a recusar os fatos ou ideias que contradizem suas crenças ou preconceitos, isto é, há tendência a buscar o conforto psíquico" (Araújo, 2021 p. 21). Percebe-se, pois, mais de uma forma concreta de desinformação.

Entre as formas manifestas de desinformação estão a pós-verdade, as fake news, as deepfakes e os fatos alternativos (Ripoll, Matos 2020b). Juntas, sustentam uma conjuntura de inverdades que, ainda assim, se blindam, disseminam e fortalecem o inconteste.

Santos, Santos e Lavigne (2020, p. 314) consideram que "temáticas como 'desinformação', 'notícias falsas' e 'pós-verdade' constituem práticas humanas orientadas a ludibriar a sociedade, partindo das distorções, dissimulações e supressões de conteúdos inscritos na realidade informacional". Nesse entendimento, podem ser enxergadas como condutas de praxe, com objetivos bem definidos.

Para Brisola e Bezerra (2018, p. 3323) "a desinformação é um sistema informacional que molda a opinião pública de acordo com seus interesses utilizando uma série de artifícios e mecanismos para manter a hegemonia". Assim, a desvirtuação e a desordem permitirão alcançar um objetivo com essa prática, em verdade, um tanto estruturada (Furtado, Oliveira 2020). Há, nesse sentido, um propósito por trás de todo o conjunto falseado e repassado às pessoas.

Muitas vezes, portanto, trata-se de uma informação manipulada para atendimento de um dado propósito, entrecortada por fatos verídicos e inexatos, ou mesmo, com teor 
robustecido para um intento específico. Vignoli, Rabello e Almeida (2021, p. 10) explicam que "para produzir desinformação poderá haver a edição compromissada em mutilar ou corromper algum fato em favor de interesses ou motivações políticas, econômicas ou de convicções ou valores".

Busca-se, via de regra, o convencimento da opinião pública. E isso é feito com intenção específica, para proveito particular (Santos, Santos, Lavigne 2020). Aspecto que torna ainda mais grave o caráter desinformador.

A desinformação consiste, pois, "em fazer com que um público ou indivíduo identifique-se com uma informação que foi manipulada e criada com o objetivo de causar prejuízo" (Furtado, Oliveira, 2020 p. 112). É fundamental, pois, saber analisar o conteúdo que se tem em mãos e quem ou o que o está repassando. Mais do que isso, "diante das múltiplas rotas informativocomunicativas, o usuário precisa saber distinguir o verdadeiro e o falso, o que é científico e o que é mera opinião" (Ferreira, Lima, Souza 2021, p. 32).

Destarte, mais do que a quantidade exorbitante de informação, tem-se um misto de informações verídicas e falsas, estas últimas propagadas até mesmo de modo intencional (Leite, Matos 2017). Logo, o problema da informação falsa é o fato de ser absorvida como verdadeira e, ainda por cima, retransmitida. Além disso, cristaliza-se no tempo e no espaço, contribuindo com a construção de pseudomemórias e com a ampliação da desinformação (Oliveira 2020).

Diante dessas questões, pode-se afirmar que a busca por soluções não advirá de um único campo do saber e, cada qual, precisa assumir sua responsabilidade no estudo do fenômeno do ato de desinformar, em sua esmagadora, contraproducente e nociva propagação. Principalmente porque o enfrentamento à desinformação representa um verdadeiro desafio (Conde, Alcará 2018). Afinal, perpassa pela conscientização das pessoas, na interrupção do ciclo de difusão de inverdades, pela construção de sistemas de informação suficientemente sólidos e confiáveis e, pela própria educação para a informação, como objeto de emancipação do sujeito.

Nessa perspectiva, a área de Biblioteconomia e Ciência da Informação tem muito a contribuir. Para tanto, contudo, deve "se atualizar epistemologicamente, e discutir o papel da informação diante do cenário crescente de desinformação" (Ripoll, Matos 2020b, p. 89). Nisso, precisa encontrar sustentação em temas que lhe são próprios. Creditam-se, então, enquanto frentes substancialmente significativas nessa argumentação: o letramento informacional e o tratamento temático da informação.

\section{LETRAMENTO INFORMACIONAL}

Em tempos de desinformação, a liberdade e a autonomia dos indivíduos precisam ser ampliadas (Bezerra 2020). E, sobretudo em ocasiões nas quais a verdade é colocada à prova, há que se atentar para o desenvolvimento de processos de confiabilidade informacional (Ripoll, Matos 2020a). O letramento informacional, conceito consolidado na Ciência da Informação (Estevão, Strauhs 2020), é um dos caminhos para tal, na medida em que possibilita o uso consciente da informação, sob chancela analítica e qualificadora do usuário.

Santos et al. (2020, p. 2) explicam que o letramento informacional reflete a "competência imbricada no processo de busca e uso eficiente, seguro e produtivo de dados, identificando sua relevância em determinado escopo". O valor está, portanto, 
no emprego efetivo e qualificado da informação que tenha sido, antes, devidamente analisada e validada.

Costa, Melo e Silva (2020, p. 468) reiteram que "devemos atentar para o papel da educação quanto ao combate à desinformação". Nesse sentido, letrar informacionalmente o cidadão é uma importante escala no âmbito do processo educacional tradicional, concedendo-Ihe autossuficiência na busca do conteúdo que considera condizente e, ao mesmo tempo, condicionando-lhe à atenção analítica de seu teor.

Conceitualmente, aliás, letramento informacional é uma condição de discernimento e análise da informação. Para Gasque (2010), consiste em um processo integrado a partir do qual se age em prol da localização, da seleção, do acesso, da organização e do uso da informação, que gera conhecimento para tomar decisões e resolver problemas. Assim, "a aprendizagem do letramento informacional (LI) possibilita desenvolver competências necessárias para saber buscar e usar a informação para algum propósito" (Gasque 2019).

Outra concepção de letramento informacional destaca a função educativa do bibliotecário no processo de construção do conhecimento científico, facilitado também pela mediação (Santos, Machado 2014). Ainda assim, não se deve esquecer do papel do próprio usuário na avaliação da informação que manipula, no que o letramento digital pode ser determinante (Boeres 2018), tendo em vista que alguém letrado informacionalmente percebe sua necessidade informacional e vai em sua procura, buscando identificar e analisar o que encontra (Blank, Gonçalves 2017).

Em certa medida, o letramento impacta na promoção social (Maranhão, Carvalho, Silva 2013), uma vez que o sujeito letrado informacionalmente divulga a informação obtida de forma ética e eficiente (Blank, Gonçalves 2017), tendo o cuidado da checagem e da apreciação acurada do conjunto antes de qualquer ação, permitindo que outros também possam usufruir de um conteúdo preciso em prol de suas necessidades. Nesse ponto, vale destacar a necessidade de integrar o usuário ao bibliotecário, que trata a informação, embora sozinho não seja capaz de resolver o problema da desinformação.

Tem-se, afinal, uma produção potencializada de conteúdos falseados, modificados e deturpados. Logo, uma ação em cadeia é, também, necessária. Projetos que integrem o profissional bibliotecário ao usuário e, vice-versa, podem auxiliar nessa demanda de disseminação consciente de informações. E isso sem relegar a este último uma postura passiva de sujeito mediado, que unicamente se apropria dos conjuntos informacionais que o primeiro organiza e processa.

Os usuários são, cada vez, mais, agentes atuantes e participativos na própria produção de conteúdo e precisam ser chamados a participar de sua ordenação. São, afinal, atores que originam informações mesmo a partir de sua navegação na rede, que gera publicidade por parte de megacorporações como Google e Facebook, configurando um espaço de novos significados, saberes e poderes (Lopes, Bezerra 2019).

Projetos integrados de letramento informacional tem sido elaborados considerando o trabalho colaborativo entre bibliotecário e professor, no contexto do ensino (Zinn, Gasque 2017). Esse prospecto precisa também ser estendido para o usuário da informação, historicamente denegado do papel de protagonista e enquadrado como sujeito mediado que recebe informações cujo tratamento tenha sido realizado pelo bibliotecário. 
Desse modo, tradicionalmente "inserido em um movimento de construção compartilhado com educadores e instituições de ensino, na busca de cumprimento de metas, formação de indivíduos e o desenvolvimento de profissionais e cidadãos" (Reis, Duarte 2017, p. 138), o letramento informacional precisa também ser enxergado sob outras nuances.

Advoga-se assim, em prol de uma atuação holística no reconhecimento dos diversos conteúdos produzidos, para o que se envida um usuário obstinado e interessado na causa, já que, ser letrado informacionalmente torna-se um desafio, ao mesmo tempo que uma necessidade premente. Afinal, convive-se com informações em formatos e meios diversos, consubstanciadas em áudio, vídeo, imagem, texto ou um misto de tudo isso, para as quais ele próprio contribui na elaboração. Outrossim, cada registro desses corporifica um tipo de conteúdo e requer uma compreensão específica em sua utilização.

Ocorre que, nesse mar de informações, a desinformação também encontra lugar, muitas vezes revestida de verdade. Pode-se afirmar até que a desinformação "circula socialmente, possui massa, peso e inércia, permanecendo em redes ou institucionalidades mais ou menos formais" (Vignoli, Rabello, Almeida 2021, p. 10), podendo estar presente em qualquer lugar ou suporte (Costa, Melo, Silva 2020).

O letramento informacional precisa, pois, ir além da simples condição de leitura e observação do conteúdo. Essencialmente porque conteúdos enganosos desafiam o cumprimento das necessidades de informação (Santos, Santos, Lavigne 2020) que cotidianamente se estabelecem. Trata-se de formar uma consciência informacional coletiva, pela interlocução individual, sujeito a sujeito.

Ademais, um olhar desconfiado, atento para o controverso, amplia as condições de uso da própria informação. Sem falar que "as tecnologias digitais mudaram de maneira decisiva a relação das pessoas com a informação" (Araújo 2021, p. 17). Tudo se difunde mais rápido, se torna mais fluido e sem controle. De modo que, a manipulação de todo esse conjunto tecnológico, juntamente com a informação por ele disseminada, representa um problema ainda não solucionado.

Há obstáculos na manipulação dos suportes, tanto quanto na construção das condições para seleção, avaliação e uso das diversas fontes informacionais na web. Programas de letramento informacional representam a via para habilitar a condição analítica e capacitante de discernir e se apropriar do que é válido e autêntico.

Vale lembrar, também, que a navegação e a pesquisa transitaram de canais institucionalizados para mídias sociais e sites comerciais. Via de regra:

\begin{abstract}
A busca informacional, na maioria das vezes, tem como ponto de partida o Google, assim como a produção de informações tem crescido significativamente em meios como o Facebook ou WhatsApp. Tais atitudes exigem práticas informacionais críticas e éticas [...]. (Zattar 2017, p. 286)
\end{abstract}

Também é importante pensar que, "assim como revolucionou a forma de recebermos informação, a internet vem redefinindo também o modo como as notícias são produzidas, apoiadas em estratégias de indexação para ganhar visibilidade" (Fernandez Júnior, Souza 2020, p. 246). De tal modo, no contexto ora vivenciado:

a migração dos mais variados aspectos da vida humana para um ambiente caracterizado pelas virtualidades do digital, faz com que a informação passe a ter representações que já não condizem mais 
com seu caráter essencial: o ato de informar. (Ripoll, Matos 2020b, p. 88)

Há, portanto, propósitos vários que não se restringem ao usuário não letrado informacionalmente, passando por estruturas influentes, projeções tendenciosas e condicionantes de sentido. Diante disso, embora cada vez mais dificultada, a dinâmica de avaliação da informação obtida torna-se cada vez mais demandada. E a chancela da adequabilidade de dado conteúdo perpassa necessariamente pelo usuário, sujeito participativo em sua produção e difusão nas distintas estruturas informacionais digitais.

Assim sendo, é preciso ter o letramento informacional como meio para que o indivíduo possa aprender como utilizar a informação, tendo criticidade e atenção desde a sua seleção. A partir disso, conseguirá aplicar e atender, sobremaneira, sua necessidade de informação. Em outras palavras:

\begin{abstract}
A aprendizagem informacional, por seu potencial de aprimoramento cognitivo e pelo desenvolvimento do senso crítico, em colaboração com processos institucionais de checagem de fatos e informações, constitui estratégia para orientar as ações das pessoas diante de suas necessidades. (Ferreira, Lima, Souza 2021, p. 32)
\end{abstract}

Contudo, apregoa-se a necessidade de agir em outras frentes. Afinal, embora universidades e organizações desenvolvam instrumentos para combate à desinformação (Santos, Santos, Lavigne 2020), de nada adianta o trabalho de checagem e validação institucional, de notícias e conteúdos digitais, se o usuário não for letrado informacionalmente para auxiliar nesse desvendar cotidiano de inverdades materializadas como desinformação. Será, na realidade, uma ação incessante.

Por isso a importância decisiva do letramento informacional e toda a sua potencialidade de operacionalização frente à informação, tanto no espectro individual quanto coletivo. Do mesmo modo, torna-se extremamente relevante o empenho de atuação conjunta no combate à desinformação, envolvendo bibliotecários, instituições e também usuários comuns.

De forma precípua, com os desafios estabelecidos no meio digital, a seleção e a busca informacionais precisam ser ainda mais cuidadosas. Afinal, a web é um fulminante meio de propagação da desinformação (Ripoll, Matos 2020b) e, canal onde ganha vulto (Brisola, Bezerra 2018). Nas redes sociais reverberam informações falsas (Santos, Santos, Lavigne 2020), o que também alerta para o cuidado com a ação de compartilhamento.

Mas, a desinformação remonta às práticas de guerra (Zattar 2017), a um contexto envolto em estratégia e à ação pautada no erro do oponente. Por isso, há verdadeiros obstáculos para se discernir a veracidade dos conteúdos (Furtado, Oliveira 2020). A capacidade de perceber o que condiz com a realidade é decisiva para uma ação individual e coletiva consciente, responsável e crítica, que virá com o letramento informacional. O que não significa que seja algo simples.

Não se deve esquecer que, embora as mídias sociais representem uma importante via para descentralização da produção de conteúdo, acabaram por amplificar a difusão de informações sem qualquer checagem ou verificação no que se refere à sua veracidade. E tudo isso com uma velocidade considerável e um alcance significativo. Perde muito o usuário da informação não letrado informacionalmente para lidar com essa 
realidade, mas, também perde a sociedade como um todo, fragilizada e exposta ao inconteste em proveito de outrem.

No fim das contas, "esse tráfego de informações por meio de novas formas de acesso e produção de conteúdo [...] tem possibilitado o consumo e disseminação de informações falsas, distorcidas, manipuladas, servindo às mais diversas finalidades pessoais e institucionais" (Leite, Matos 2017, p. 2336). Valendo-se justamente da rapidez e do alcance das mídias sociais, a desinformação se amplifica e favorece o interesse de poucos.

O letramento informacional representa, então, um caminho para frear a desinformação. Principalmente porque "incrementar a capacidade de reflexão crítica do leitor frente ao conteúdo que consome é um dos caminhos almejáveis para que se compartilhe informações com qualidade" (Conde, Alcará 2018, p. 1615). Não se trata exclusivamente de retirar de circulação toda e qualquer informação falseada e manipulada, que constitui operação improvável pelo surgimento constante de outras de mesmo caráter, mas sim, de condicionar o cidadão a analisar e circunstanciar os conteúdos que lhe chegam.

Por conta disso, o letramento informacional tem potencial para enriquecer o saber coletivo. E, além disso, beneficiar a disseminação sadia e propositiva de conteúdos, analisados antes de reenviados, ponderados em sua essência e estimados em sua qualidade. Essencialmente, pois, difundidos com compromisso e responsabilidade.

Há que se atentar, ainda, para o grave fato de que a leitura e a interpretação venham perdendo espaço para a desinformação, incorrendo em comportamentos informacionais mecanicamente orquestrados pela população (Leite, Matos 2017). Dessa forma, o letramento informacional tem um relevante papel a cumprir com seu caráter condicionante da reflexão e da avaliação sobre a informação que é obtida, mesmo em circunstâncias tão desafiadoras como as que são enfrentadas, perpassando até mesmo pelo aspecto comportamental.

Destarte, embora se estabeleça como instrumento potencial para combater a desinformação, o letramento informacional precisa ser trabalhado em conjunto com outras estratégias. Inclusive porque Revez e Corujo (2021) explicam que, para além de uma postura otimista, a literatura também tem demonstrado que o domínio da pesquisa de informação e as habilidades para sua avaliação podem não ser mais eficientes.

Nesse sentido, a responsabilidade de investigar e compreender o letramento informacional aumenta. Representa um meio para aclarar todas as suas facetas e propriamente suas limitações. Ademais, é um caminho para ampliar seu escopo e suas condições integradas de atuação.

Outra perspectiva é a de que "o fomento à competência crítica em informação deveria acompanhar a educação ao longo da vida para, dentre outras habilidades, ajudar a formar cidadãos aptos a lidar com fenômenos informacionais como a desinformação e a circulação de fake news" (Brisola, Bezerra 2018, p. 3327). Entendendo como letramento ou competência, o importante é a ação condicionante para seleção acurada de informação, que em muito pode se beneficiar do tratamento temático e sua pontual representação do teor informacional. 


\title{
TRATAMENTO TEMÁTICO DA INFORMAÇÃO
}

Deve-se reconhecer que "diversos atributos da informação já foram estudados (relevância, qualidade, exatidão, acessibilidade, etc.), mas sua condição de ser "verdadeira" nunca esteve entre elas" (Araújo 2021, p. 26). Por isso o enfoque ora estabelecido, buscando inter-relacionar letramento informacional e tratamento temático, compelidos pela desinformação.

Conforme supramencionado, reitera-se que notícias falsas são um desafio para as bibliotecas (Revez, Corujo 2021). Depreende-se, pois, um papel incisivo do bibliotecário na mitigação da prática de desinformar. De forma concreta, a partir de sua atuação em projetos de letramento informacional, que habilitem os usuários na pesquisa consciente da informação, com olhar seletivo e analítico para os conjuntos recuperados nas bases de dados. Mas, além disso, em ações que ultrapassem os muros das bibliotecas e centros informacionais, que cheguem à população em geral, mediante o aporte laboral de trato informacional, estendido a todo e qualquer tipo de conteúdo.

No universo da organização da informação pode-se especificar, diretamente: a dimensão de tratamento descritivo e a dimensão de tratamento temático. Coordenadamente desenvolvidas, dão lugar a representações de caráter formal e de conteúdo, substanciais para a pesquisa e recuperação de informações.

Desse modo, a perspectiva dual de tratamento descritivo e temático da informação (Sousa 2013) permite enxergar um valoroso trabalho de especificação dos atributos físico-formal e de conteúdo, contidos na informação. Destes, derivam as condições para a busca e recuperação da informação.

Tratar informação é, afinal, uma relevante função em bibliotecas (Dias, Naves 2013). Destarte, com o tratamento temático da informação, encarregado de identificar assuntos (Guedes 2009), propicia-se a acessibilidade temática e, embora se trate de um processo subjetivo (Dal'Evedove, Fujita 2013) e desafiador em sua condução (Sousa 2013), circunda a informação e o usuário (Redigolo, Silva 2017). O TTI também se configura como "dimensão fundamental em Organização da Informação" (Oliveira, Grácio, Martínez-Ávila 2020, p. 44), detida ao que Guimarães (2008) explicita como a instância do "sobre o que" um documento trata.

O TTI atua, ainda, como mediador do acervo informacional (Redigolo, Silva 2017). Por se tratar de uma dimensão organizativa do conteúdo (Oliveira, Grácio, Martínez-Ávila 2020), tem grande responsabilidade na especificação da informação, a partir do assunto nela congregado. Sobretudo ao se considerar o aumento exponencial das informações produzidas. Há que se atentar, basicamente, que:

\begin{abstract}
Juntamente com o crescimento documentário, cresce também a necessidade de se reforçar a representação da informação, e desta forma pensar/discutir sobre a representação temática, ou seja, aumenta-se a preocupação em tornar o documento singularmente representado. (Redigolo, Silva 2017, p. 54)
\end{abstract}

É justamente a descrição do conteúdo que tornará viável a individualização dos assuntos simples e compostos. Também será determinante para a seleção da informação em bases de dados e outros sistemas de recuperação da informação, diante das informações documentárias obtidas na forma de palavras-chave e resumos documentários. Dessa forma, conforme Gracioso, Martínez-Ávila e Simões (2019), o TTI vai de encontro à produção de novos conhecimentos, potencializando-a. 
Justifica-se, assim, a constante preocupação do TTI de possibilitar o acesso ao assunto contido em um documento (Sousa 2013). E, ainda que tardiamente tornado tema central de pesquisa na Ciência da Informação (Albrechtsen 1993), o tratamento temático da informação é parte substancial dessa área, fundamentando um entorno aplicado, na Biblioteconomia, que incide sobre a representação do teor documental.

Há o entendimento de que o entorno teórico do tratamento temático da informação precisa ser mais explorado (Oliveira, Grácio, Martínez-Ávila 2020). Também se envida uma melhor sistematização de suas práticas (Pando 2018), a partir do estabelecimento de referenciais aplicados. Como já apregoado por Foskett (1973), em sua clássica obra "The subject approach to information", há graves problemas a serem resolvidos na abordagem temática.

Desafios não faltam, pois, à concretização do TTI. Afinal, sua operacionalização não se restringe à técnica (Guedes 2009). Sousa (2013, p. 137) fala, inclusive, que "o uso da tecnologia no tratamento da informação alavancou não apenas facilidades, mas também desafios aos bibliotecários". Não apenas pela difusão amplificada de conteúdos, que ganham corpo em meio digital, posto que uma distinção de ferramentas e softwares incita um repensar de funções e padrões tradicionalmente desenvolvidos e aplicados, assim como se institui uma representação temática, de modo cada vez mais frequente, pelas mãos do produtor de conteúdo na web.

O tratamento temático segue, em verdade, cumprindo relevante papel na representação da informação corporificada em meio físico ou digital, sendo enormemente necessário para o estabelecimento, a especificação e a individualização dos assuntos que contém. $E$, embora se possa contar com as tecnologias digitais e certa facilidade de acessar conteúdos variados na Internet (Ascoli, Galindo 2021), essa condição facilitada e simples de recuperá-los não se efetiva na prática, uma vez que o meio digital demanda, também, acurados processos de representação e arranjo para adequada visualização, pesquisa e seleção das informações que congrega.

Outrossim, a condição de busca por assunto propiciada pelo TTI acaba sendo desafiada diante dos conteúdos falaciosos, estruturados com a finalidade de distorcer e confundir o usuário. De fato, a desinformação representa uma ameaça ao conhecimento (Furtado, Oliveira 2020).

De modo que, entre fontes digitais confiáveis e fundamentadas, ganham lugar canais e estruturas sem checagem de seu teor e daquilo que noticiam ou informam, cujo teor precisa ser esmiuçado e compreendido em sua validade e adequabilidade. Nesse contexto, o tratamento temático da informação ganha ainda mais importância, seja na operação de representação do conteúdo, seja na ação individualizante dos itens informacionais por seu atributo temático.

O TTI se reveste, então, de um caráter responsivo ainda maior. O bibliotecário precisa viabilizar a busca por assunto tanto quanto o alcance de informações válidas e confiáveis. Não é à toa que, conforme Santos, Santos e Lavigne (2020), esse profissional tem se engajado cada vez mais no combate à desinformação, juntamente com profissionais da tecnologia e da comunicação.

Destarte, é preciso tratar tematicamente a informação pensando diretamente em seu alcance. Um termo pode, afinal, invalidar uma busca ao invés de viabilizar o acesso. A intersecção aqui sinalizada diz respeito ao criterioso ato de dizer do que trata um documento, circunspecto e atento o suficiente para evidenciar o conteúdo e fazê-lo chegar ao usuário. 
Entretanto, trata-se de transmutar o acurado trabalho do bibliotecário de tratar tematicamente a informação, revestindo-a de um caráter social de dinâmica mais efusiva e de alcance mais amplo. Sobretudo ultrapassando os muros do tradicional universo documentário-representacional, fazendo chegar o TTI àquele conteúdo básico manuseado dia-a-dia.

A orientação sobre o uso da informação, nos círculos familiares e de amigos, é o primeiro passo, para que assim se possa evoluir para a formação de uma consciência de representação do conteúdo utilizado. Até mesmo para demarcar sua falibilidade ou inconsistência.

A atuação do bibliotecário em projetos sociais e a nível de voluntariado é outra via para a prática da educação para a informação, incluindo a orientação para representação do teor dos conteúdos digitais. Embora, conforme Santos, Santos e Lavigne (2020), seja crucial conhecer a necessidade de informação para então refutar certos conteúdos e fontes informacionais, há que se reconhecer a enormidade de estruturas e meios pelas quais informações inverídicas circulam diariamente, de modo que contra atuar com ações mais incisivas e de intervenção, no prisma do usuário, acaba funcionando como uma forma de combate à desinformação.

Dentro dessa prerrogativa, o bibliotecário deve compreender que não é exclusivamente a informação institucionalizada que irá atender à demanda de um usuário. Muitas vezes é justamente um conteúdo abstrato ou informal, altamente suscetível à deformação e à transformação em desinformação. Em razão disso esse profissional precisa se "atentar aos desafios que extrapolam o cumprimento de sua atividade intelectual e técnica, como reconhecer notícias que procuram desinformar os leitores" (Santos, Santos, Lavigne 2020, p. 313), condicionando o usuário a rotulá-las como tal.

Uma atuação reflexiva no tratamento temático da informação, por parte do profissional, é, do mesmo modo, fundamental. O bibliotecário precisa abstrair o alcance de sua ação na representação dos assuntos, que condiciona o acesso, podendo também inviabilizá-lo. A depender daquilo que enfatiza, o conteúdo pode se misturar a outro de caráter duvidoso, associando-se e validando de alguma forma, esse último.

Apesar disso, o bibliotecário não pode esquecer das manifestações comportamentais negativas estimuladas pela desinformação (Santos, Santos, Lavigne 2020). Em suma, terá seu trabalho de representação de assunto desafiado até mesmo por estruturas de software, perfis falsos, tagueamento tendencioso indutor de cliques e uma gama de outros elementos. Dessa forma, mais do que representar conteúdo, será preciso representar com fidedignidade e atenção, para creditar validade e exatidão aos metadados que conduzem à informação verdadeira, completa e original.

Outrossim, "a essência da atividade documentária está naquele que busca a informação, o usuário" (Jesus, Alves 2019, p. 116), em prol do qual todo o trabalho de trato informacional se justifica, inclusive. Mas, de nada adianta se a informação tratada tematicamente não refletir as intenções de pesquisa e o construto de conteúdos almejados pelo usuário. Por isso a importância de que o teor dos documentos seja inteiramente coberto, detalhadamente representado e cuidadosamente evidenciado, o que indiretamente culminará em uma condição assertiva para lidar com o excesso de fontes informação e a miríade de assuntos de que falam Santos, Santos e Lavigne (2020).

Há que se atentar, ademais, para a desigualdade no acesso à informação e a incapacidade de compreensão de informações novas ou complexas, intensificadas 
pela desinformação (Revez, Corujo 2021). Nesse ponto o tratamento temático da informação também pode auxiliar sobremaneira, juntamente com o letramento informacional.

O estabelecimento de atributos temáticos não converge apenas para a busca, mas, fundamentalmente, para a sinalização e evidência de determinado aspecto que aquela informação congrega. O letramento informacional pode inculcar no usuário a cautela de visualizar os pontos de acesso temáticos e já começar, nesse ponto, a avaliar a conformidade do conjunto informacional que tem em mãos.

É possível pensar, então, em uma intersecção entre letramento informacional e tratamento temático, que dê conta de abarcar o fenômeno desinformação, contribuindo para sua minimização, no que se refere às suas formas manifestas sobretudo, em meio digital.

\section{CONCLUSÕES}

A pesquisa buscou discorrer teoricamente sobre o vínculo das instâncias de processamento e de uso da informação, na figura do tratamento temático e do letramento informacional, tendo por base o pilar da desinformação. Salienta-se, individualmente, o papel do LI e do TTI no ato de suplantar a desinformação, como também evidenciam-se contributos conjuntos, em razão da característica dinâmica, desafiadora e enredada que $o$ ato de desinformar conspurca.

A integração do letramento informacional e do tratamento temático da informação é, de certo modo, incitada pela cultura da desinformação, representando um meio para o manuseio analítico dos distintos conteúdos e o real combate à sua distorção e desvirtuação. Todavia, dirimi-la passa pela ação integrada de bibliotecários, instituições e usuários.

Estudos futuros podem se dedicar a estabelecer critérios de tratamento temático orientado para suprimir informações falseadas e distorcidas em seu teor, tendo por base o caráter analítico de assunto observado por bibliotecários durante as operações desse macroprocesso. Outra possibilidade é o aprofundamento teórico nas ações envoltas no letramento informacional, visando correlacioná-las a práticas de desinformação comumente observadas, buscando estabelecer um modelo referencial de checagem e validação instrucional da informação.

\section{AGRADECIMENTOS}

Ao Instituto Federal de Goiás, no qual o projeto de pesquisa que originou este estudo, está cadastrado.

À Universidade Federal de Goiás, cujo afastamento para cursar doutorado, permitiu o desenvolvimento deste estudo.

\section{REFERÊNCIAS}

ALBRECHTSEN, Hanne, 1993. Subject analysis and indexing: from automated indexing to domain analysis. The Indexer, vol. 18, no. 4. [Acesso em 10 junho 2021]. Disponível 
em:

https://pdfs.semanticscholar.org/d124/b3c48d681d2cd77f612ee2d9602850747e07.pdf

ARAÚJO, Carlos Alberto Ávila, 2021. A pós-verdade como desafio central para a Ciência da Informação contemporânea. Em Questão, vol. 27, no. 1, p. 13-29. [Acesso em 10 fevereiro 2021]. Disponível em: https://seer.ufrgs.br/EmQuestao/article/view/101666/59067

ASCOLI, Arabelly; GALINDO, Marcos, 2021. A quarta revolução e a necessária reinvenção da Biblioteconomia. Encontros Bibli: Revista Eletrônica de Biblioteconomia e Ciência da Informação, vol. 26, p. 1-21. [Acesso em 22 fevereiro 2021]. Disponível em: https://periodicos.ufsc.br/index.php/eb/article/view/75961/45207

BAPTISTA, Dulce Maria, 1994. Do caos documentário à gerência da informação. Ciência da Informação. vol. 23, no. 2, p. 239-248. [Acesso em 14 fevereiro 2021]. Disponível em: https://brapci.inf.br/_repositorio/2010/03/pdf_2482cdf341_0008906.pdf

BERNARDINO, Maria Cleide Rodrigues; SAMPAIO, Denise Braga, 2019. Tangências e consequências da sociedade informática e da pós-verdade: o potencial papel da biblioteca pública. PontodeAcesso, vol. 13, no. 3, p. 141-155. [Acesso em 09 dezembro 2020]. Disponível em: https://periodicos.ufba.br/index.php/revistaici/article/view/34902/20744

BEZERRA, Arthur Coelho, 2020. Da teoria matemática para uma proposta de teoria crítica da informação: a integração dos conceitos de regime de informação e competência crítica em informação. Perspectivas em Ciência da Informação, vol. 25, no. 3, p. 182-201. [Acesso em 15 dezembro 2020]. Disponível em: http://portaldeperiodicos.eci.ufmg.br/index.php/pci/article/view/4026

BLANK, Cintia Kath; GONÇALVES, Renata Braz, 2017. Projeto de letramento informacional para estudantes do ensino fundamental: relato de experiência. Revista ACB: Biblioteconomia em Santa Catarina, vol. 22, no. 1, p. 104-117. [Acesso em 12 dezembro 2020]. Disponível em: https://revista.acbsc.org.br/racb/article/view/1269/pdf

BOERES, Sonia, 2018. O letramento e a organização da informação digital aliados ao aprendizado ao longo da vida. Revista Digital de Biblioteconomia \& Ciência da Informação, vol. 16, no. 2, p. 483-500. [Acesso em 10 fevereiro 2021]. Disponível em: https://periodicos.sbu.unicamp.br/ojs/index.php/rdbci/article/view/8651507/pdf

BRISOLA, Anna; BEZERRA, Arthur Coelho, 2018. Desinformação e circulação de "fake news": distinções, diagnóstico e reação. Em: Encontro Nacional de Pesquisa em Ciência da Informação. Londrina: UEL. 2018. 19. [Acesso em 10 fevereiro 2021]. Disponível em: http://enancib.marilia.unesp.br/index.php/XIX_ENANCIB/xixenancib/paper/view/1219

BRITO, Vladimir de Paula; PINHEIRO, Marta Macedo Kerr, 2015. Poder informacional e desinformação. Em: Encontro Nacional de Pesquisa em Ciência da Informação. João Pessoa: UFPB. 2015. 16. [Acesso em 20 dezembro 2020]. Disponível em: http://www.ufpb.br/evento/index.php/enancib2015/enancib2015/paper/view/2677

CONDE, César Augusto Galvão Fernandes; ALCARÁ, Adriana Rosecler, 2018. Desinformação: qualidade da informação compartilhada em mídias sociais. Em: Encontro Nacional de Pesquisa em Ciência da Informação. Londrina: UEL. 2018. 19. 
[Acesso em 16 dezembro 2020]. Disponível

em: https://brapci.inf.br/index.php/res/v/102482

COSTA, Fernanda C. S.; MELO, Daniella Alves de; SILVA, Laelson Felipe da, 2020. A importância da coleção feminismos plurais no enfrentamento à desinformação sobre as questões étnico-raciais dos afro-brasileiros. Em: SILVA, Franciéle Carneiro Garcês da (org.).Bibliotecári@s negr@s: pesquisas e experiências de aplicação da Lei 10.639/2003 na formação bibliotecária e nas bibliotecas. Florianópolis: Rocha Gráfica e Editora. p. 463-478.

DAL'EVEDOVE, Paula Regina; FUJITA, Mariângela Spotti Lopes, 2013. Estudo sociocultural da comunidade discursiva do tratamento temático da informação em bibliotecas universitárias. Encontros Bibli: Revista Eletrônica de Biblioteconomia e Ciência da Informação, vol. 18, no. 36, p. 23-50. [Acesso em 10 junho 2021]. Disponível em: https://periodicos.ufsc.br/index.php/eb/article/view/1518-

2924.2013v18n36p23/24526

DIAS, Eduardo Wense; NAVES, Madalena Martins Lopes, 2013. Análise de assunto: teoria e prática. Brasília: Thesaurus.

ESTEVÃO, Janete Saldanha Bach; STRAUHS, Faimara do Rocio, 2020. Letramento informacional para reuso de dados nas ciências sociais: requisitos e competências. Informação \& Informação, vol. 25, no. 2, p. 1-25. [Acesso em 20 dezembro 2020]. Disponível em: http://www.uel.br/revistas/uel/index.php/informacao/article/view/38995/pdf

FERNANDEZ JÚNIOR, Fernando Ewerton; SOUZA, Rosali Fernandez de, 2020. Critérios de relevância e classificação política no discurso jornalístico internacional. Perspectivas em Ciência da Informação, vol. 25, no. 2, p. 244-261. [Acesso em 22 dezembro 2020]. Disponível em: https://periodicos.ufmg.br/index.php/pci/article/view/24127/19439

FERREIRA, João Rodrigo Santos; LIMA, Paulo Ricardo Silva; SOUZA, Edivanio Duarte de, 2021. Desinformação, infodemia e caos social: impactos negativos das fake news no cenário da COVID-19. Em Questão, vol. 27, no. 1, p. 30-58. [Acesso em 19 fevereiro 2021]. Disponível em: https://seer.ufrgs.br/EmQuestao/article/view/102195/59076

FOSKETT, Antony Charles, 1973. A abordagem temática da informação. Tradução de Antonio Agenor Briquet de Lemos. São Paulo: Polígono; Brasília: Ed. Universidade de Brasília.

FURTADO, Renata Lira; OLIVEIRA, Jenifer Galdino de, 2020. O fenômeno desinformação sob a perspectiva dos arquivistas brasileiros: o papel da competência em informação. Informação em Pauta, vol. 5, no. 2, p. 107-131. . [Acesso em 13 dezembro 2020]. Disponível em: http://www.periodicos.ufc.br/informacaoempauta/article/view/60391/162623

GASQUE, Kelley Cristine Gonçalves Dias, 2010. Arcabouço conceitual do letramento informacional. Ciência da Informação, vol. 39, no. 3, p. 83-92 . [Acesso em 11 janeiro 2021]. Disponível em: http://revista.ibict.br/ciinf/article/view/1268/1446 
GASQUE, Kelley Cristine Gonçalves Dias, 2019. O processo de atenção e o letramento informacional. Em Questão, vol. 25, no. 3, p. 61-80. [Acesso em 19 dezembro 2020]. Disponível em: https://seer.ufrgs.br/EmQuestao/article/view/87998/53598

GRACIOSO, Luciana de Souza; MARTÍNEZ-ÁVILA, Daniel; SIMÕES, Maria da Graça de Melo, 2019. "Tratamento Temático da Informação" na pesquisa Brasileira em Ciência da informação: percursos e relações. Scire, vol. 25, no. 2, p. 23-34. [Acesso em 10 junho 2021]. Disponível em: https://ibersid.eu/ojs/index.php/scire/article/view/4647

GUEDES, Emanuel Guedson Ferreira, 2009. O conceito aboutness na organização e representação do conhecimento. 90 f. Dissertação (Mestrado em Ciência da informação) - Faculdade de Filosofia e Ciências, Universidade Estadual Paulista, Marília, 2009. [Acesso em: 10 junho 2021]. Disponível em:

https://repositorio.unesp.br/bitstream/handle/11449/93659/guedes_egf_me_mar.pdf? sequence $=1$ \&isAllowed $=y$

GUIMARÃES, José Augusto Chaves, 2008. A dimensão teórica do tratamento temático da informação e suas interlocuções com o universo científico da International Society for Knowledge Organization (ISKO). Revista Ibero-Americana de Ciência da Informação, vol. 1, no. 1, p. 77-99. [Acesso em 10 junho 2021]. Disponível em: http://periodicos.unb.br/index.php/RICI/article/view/940/815

JESUS, Joselito Manoel de; ALVES, Fernanda Maria Melo, 2019. Meyriat, Foskett e a competência em informação. PontodeAcesso, vol. 13, no. 3, p. 115-127. [Acesso em 13 dezembro 2020]. Disponível em:

https://periodicos.ufba.br/index.php/revistaici/article/view/35222/20741

LOPES, Bianca da Costa Maia; BEZERRA, Arthur Coelho, 2019. Entre hiperinformação e desinformação: o "fio de Ariadne" para a preservação da informação na web. Liinc em Revista, vol. 15, no. 1, p. 261-274. [Acesso em 16 dezembro 2020]. Disponível em: http://revista.ibict.br/liinc/article/view/4605/4149

MARANHÃO, Samantha de Moura; CARVALHO, Germênia Alves; SILVA, Gregório Jefferson da, 2013. Letramento informacional: uma modalidade de ascensão social. Múltiplos Olhares em Ciência da Informação, vol. 3, no. 2. [Acesso em 13 dezembro 2020]. Disponível em: https://periodicos.ufmg.br/index.php/moci/article/view/17545/14328

OLIVEIRA, Bernardina Maria Juvenal Freire de, 2020. Pseudomemórias: o rosto visível e episódico das fake news. Em: OLIVEIRA, Maria Amália Silva Alves de; CURCINO, Alan; COSTA, Luciana Ferreira da; MAGALHÃES, Fernando (coord.). Ensaios sobre memória. Escola Superior de Educação e Ciências Sociais - Politécnico de Leiria. p. 169-191.

OLIVEIRA, Lais Pereira de; GRÁCIO, Maria Cláudia Cabrini; MARTíNEZ-ÁVILA, Daniel, 2020. Instrumentos, processos e produtos do Tratamento Temático da Informação: um estudo nos anais da ISKO-Brasil (2012-2019). Scire, vol. 26, no. 1, p. 47-56. [Acesso em 10 junho 2021]. Disponível em: https://www.ibersid.eu/ojs/index.php/scire/article/view/4681/4253

PANDO, Daniel Abraão, 2018. Epistemologia da organização da informação: uma análise de sua cientificidade no contexto brasileiro. $463 \mathrm{f}$. Tese (Doutorado em Ciência da Informação) - Faculdade de Filosofia e Ciências, Universidade Estadual Paulista Júlio de 
Mesquita Filho, Marília, 2018. [Acesso em 10 junho 2021]. Disponível em: https://repositorio.unesp.br/bitstream/handle/11449/153395/pando_da_dr_mar.pdf?se quence=3\&isAllowed $=y$

REDIGOLO, Franciele Marques; SILVA, Marli Vitor da, 2017. A representação temática como mediadora implícita da informação em bibliotecas universitárias. PontodeAcesso, vol. 11, no. 2, p. 49-69. [Acesso em 10 junho 2021]. Disponível em: https://periodicos.ufba.br/index.php/revistaici/article/view/14307/15195

REIS, Giordani Avila; DUARTE, Adriana Bogliolo Sirihal, 2017. Leitura e letramento informacional na universidade: um hiato, um construto fragmentado ou um dilema?. Informação \& Informação, vol. 22, no. 3, p. 136-157. [Acesso em 10 dezembro 2020]. Disponível em: http://www.uel.br/revistas/uel/index.php/informacao/article/view/26075/22729

REVEZ, Jorge; CORUJO, Luís. Librarians against fake news: a systematic literature review of library practices, 2021. The Journal of Academic Librarianship, no. 47, p. 1-9. [Acesso em 16 fevereiro 2021]. Disponível em: https://www.sciencedirect.com/science/article/abs/pii/So099133320301956

RIPOLL, Leonardo; MATOS, José Cláudio Morelli, 2020a. Desinformação e informação semântica: a Filosofia da Informação e o pensamento de Luciano Floridi na contribuição à confiabilidade informacional. Em Questão, vol. 26, no. 2, p. 211-232. [Acesso em 11 janeiro 2021]. Disponível em: https://seer.ufrgs.br/EmQuestao/article/view/90428/56062

RIPOLL, Leonardo; MATOS, José Cláudio Morelli, 2020b. O contexto informacional contemporâneo: o crescimento da desinformação e suas manifestações no ambiente digital.Informação@Profissões, vol. 9, no. 1, p. 87-107. [Acesso em 16 dezembro 2020]. Disponível em:

http://www.uel.br/revistas/uel/index.php/infoprof/article/view/38212/pdf

SANTOS, Alana Driziê Gonzatti dos; PEREIRA, Dayveson Noberto da Costa; MORAIS, Felipe Augusto Souza; LEMOS, Maria Clara Lucena de, 2020. Letramento informacional, Covid-19 e infodemia. Liinc em Revista, vol. 16, no. 2, p. 1-24. [Acesso em: 11 janeiro 2021]. Disponível em: http://revista.ibict.br/liinc/article/view/5214/5095

SANTOS, Fabiana Pereira; MACHADO, Lucilia Regina de Souza, 2014. O papel do bibliotecário de referência na construção do letramento informacional acadêmico: uma prática intersetorial e interdisciplinar. InCID: Revista de Ciência da Informação e Documentação, vol. 5, no. 2, p. 142-163. DOI: [Acesso em 13 dezembro 2020]. Disponível em: https://www.revistas.usp.br/incid/article/view/76319/87552

SANTOS, José Carlos Sales dos; SANTOS, Vagner Marcelo Ramos; LAVIGNE, Fabiana Costa, 2020. Desinformação, pós-verdade e comportamento humano: discussões plausíveis. Biblos: Revista do Instituto de Ciências Humanas e da Informação, vol. 34, no. 2, p. 313-331. [Acesso em 11 janeiro 2021]. Disponível em: https://periodicos.furg.br/biblos/article/view/11368/8452

SOUSA, Brisa Pozzi de, 2013. Representação temática da informação documentária e sua contextualização em biblioteca. Revista Brasileira de Biblioteconomia e Documentação, São Paulo, vol. 9, no. 2, p. 132-146. [Acesso em 10 junho 2021]. Disponível em: https://rbbd.febab.org.br/rbbd/article/view/249/265 
VIGNOLI, Richele Grenge; RABELLO, Rodrigo; ALMEIDA, Carlos Cândido de, 2021. Informação, misinformação, desinformação e movimentos antivacina: materialidade de enunciados em regimes de informação. Encontros Bibli: Revista Eletrônica de Biblioteconomia e Ciência da Informação, vol. 26, p. 1-31. [Acesso em 10 fevereiro 2021]. Disponível em: https://periodicos.ufsc.br/index.php/eb/article/view/75576/45205

WILKE, Valéria Cristina Lopes, 2020/2021. Pós-verdade, fake news e outras drogas: vivendo em tempos de informação tóxica. Logeion: Filosofia da Informação, vol. 7, no. 1, p. 8-27. [Acesso em 10 fevereiro 2021]. Disponível em:

http://revista.ibict.br/fiinf/article/view/5427/4996

ZATTAR, Marianna, 2017. Competência em informação e desinformação: critérios de avaliação do conteúdo das fontes de informação. Liinc em Revista, vol. 13, no. 2, p. 285-293. [Acesso em 11 janeiro 2021]. Disponível em:

http://revista.ibict.br/liinc/article/view/4075/3385

ZINN, Alexandra César; GASQUE, Kelley Cristine Gonçalves Dias, 2017. A construção de um programa de letramento informacional e arte educação. Revista Digital de Biblioteconomia e Ciência da Informação, vol. 15, no. 1, p. 171-188. [Acesso em 11 janeiro 2021]. Disponível em:

https://periodicos.sbu.unicamp.br/ojs/index.php/rdbci/article/view/8646067/pdf 